Kayan Araújo, Verônica Garcia Donoso e Luan Rodrigo dos Santos Cavaleiro

\title{
Processo de intervenção urbana colaborativa no centro comercial do Conjunto Jardim Maguari, Belém, Pará
}

Collaborative urban intervention in the Jardim Maguari housing complex's comercial center, in Belém, Pará

Kayan Freitas de Araújo*, Verônica Garcia Donoso**, Luan Rodrigo dos Santos Cavaleiro***

*Mestrando pelo PPGAUP (UFSM/RS). Arquiteto e Urbanista pela Faculdade Estácio de Belém. É pesquisador do grupo QUAPÁ-FAUUSP desde 2020, pesquisando sobre o Sistema de Espaços Livres (SEL) e a forma urbana, kayan.araujo@acad.ufsm.br

**Professora Adjunta no curso de Arquitetura e Urbanismo da UFSM. É mestra e doutora pela FAUUSP (2011 e 2017). É pesquisadora do grupo QUAPÁ-FAUUSP desde 2009, pesquisando sobre o Sistema de Espaços Livres (SEL) e a forma urbana. Tem experiência na área de Planejamento da Paisagem e Projeto do Espaço Urbano, veronica.donoso@ufsm.br

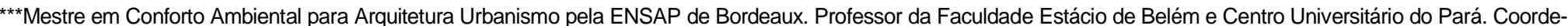
nador do Escritório Modelo de Arquitetura de Interesse Social da Estácio, luancavaleiro@gmail.com

\section{Palavras-chave:}

Equipamento urbano;

Gestão colaborativa;

Urbanismo tático.

\section{Keywords:}

Urban equipment;

Collaborative management;

Tactical urbanism.

\section{Resumo}

O centro comercial do Conjunto Jardim Maguari, ativo desde a década de 1980, caracteriza-se pela diversidade em atividades econômicas, estruturas permanentes e de uso misto. O espaço, considerado um equipamento urbano desejável e necessário para qualidade do ambiente urbano, atende parte da população do bairro do Coqueiro, em Belém/PA, contribuindo com o fluxo intenso de pessoas durante o dia. O uso constante do espaço urbano, combinado com outras circunstâncias, aceleraram a deterioração e degradação do ambiente, uma vez que não são feitas a manutenção e/ou readaptações urbanas necessárias periodicamente. À vista desse cenário, propõe-se com este artigo apresentar os resultados de uma pesquisa experimental realizada no centro comercial como produto para estudo do urbanismo tático caracterizado pelo aspecto colaborativo, de baixo custo e flexível, como alternativa à intervenção no ambiente construído em pequena escala, para recuperação física e de redirecionamento da ocupação do espaço público. Para tanto, o texto busca analisar qualitativamente o urbanismo tático a partir do detalhamento do processo de intervenção urbana e dos resultados obtidos e, com isso, fomentar discussões sobre metodologias de intervenção urbana alternativas como instrumento para autonomia na gestão colaborativa do espaço público.

\section{Abstract}

The Conjunto Jardim Maguari's commercial center, active since the 1980 s, is characterized by diversity in economic activities, permanent structures and mixed use. The space, considered a desirable and necessary urban equipment for the quality of the urban environment, serves part of the population of the Coqueiro's neighborhood, in Belém/PA, conurban space, combined with other circumstances, accelerated the deterioration and degradation of the environment, since the necessary urban maintenance and/or retrofitting is not done periodically. In view of this scenario, it is proposed with this article to present the results of an experimental research carried out at the commercial center as a product for the study of tactical urbanism characterized by the collaborative aspect, of low cost and flexible, as an alternative to intervention in the environment built on a small scale, for physical recovery and redirecting the occupation of public space. Therefore, the text seeks to qualitatively analyze tactical urbanism through the detailing of the urban intervention process and of the results obtained and, with this, to encourage discussions on alternatives urban intervention methodologies as an instrument for autonomy in the collaborative management of public space. 


\section{Introdução}

O método tradicional de planejamento urbano, cujos protagonistas na produção do espaço são "autoridades que controlam o processo e decidem o quê e como serão implementadas as ações urbanas" (MACÊDO; ALMEIDA, 2018, p. 2), algumas vezes desconsidera características locais no processo de intervenção urbana, de modo a produzir espaços que não se conectam à comunidade, em especial, relacionado à aspectos culturais e sociais. Nessa perspectiva, a conexão com o espaço e as relações de pertencimento e de memórias são suprimidas ou esquecidas no processo de planejamento urbano (GEHL, 2013).

Para Gehl (2004, p. 73), "a familiaridade com os sentidos do ser humano - como eles funcionam e as áreas em que trabalham - é um importante requisito para desenhar e dimensionar todas as formas de espaços ao ar livre e disposição de edif́cios". Sendo assim, iniciativas colaborativas atuam no espaço público com o objetivo de melhorar a qualidade do ambiente urbano e, consequentemente, de vida da população.

As intervenção urbanas colaborativas, compreendidas como ações sobre o espaço urbano, buscam evitar ou incentivar transformações em espaços livres da cidade por meio da cooperação entre diversos grupos sociais (comunidade, técnicos, políticos, etc.). Além disso, dispõem de ferramentas de intervenção urbana acessíveis financeiramente, portanto, de baixo custo, e se apresentam como alternativa ao método tradicional de planejamento urbano, frequentemente de alto custo, execução em longo prazo e pouco participativo (MACÊDO; ALMEIDA, 2018).

Dentre as ferramentas de intervenção urbana colaborativa está o urbanismo tático, que se conceitua como instrumento de intervenção urbana inspirado em metodologias de produção flexíveis, participativas, de baixo custo e efêmeras, estabelecido por meio da iniciativa de grupos compostos por representantes de comunidades, instituições públicas ou privadas e do governo (LYDON; GARCIA, 2015). A perspectiva colaborativa, associada a esta metodologia de intervenção, é entendida como alternativa e avanço ao método tradicional de planejamento urbano, geralmente burocrático e autoritário (AHMAD, 2017).

Lydon e Garcia (2015) referenciam o termo tático associado ao urbanismo a estratégia ou planejamento. Conforme os autores, essas iniciativas são adjetivadas dessa forma porque: "usam um meio deliberado e acessível para atingir objetivos predefinidos enquanto incorporam flexibilidade ao processo de planejamento e entrega do projeto" (LYDON, GARCIA, 2015, p. 215). Conforme os autores, o urbanismo tático pode ser utilizado para modificar o desenho urbano, remodelando espaços com identidades visuais atrativas e criativas, como projeto piloto ou alternativa para recuperação ou criação de espaços públicos de maneira menos complexa, isto é, a partir da apropriação de iniciativas táticas: metodologia e objetivos acessíveis que atuam em prol de resultados significativos e rápidos.

As características apresentadas sobre o urbanismo tático ajudam a compreender a preferência dessa ferramenta em práticas de intervenção urbana, principalmente, de iniciativa popular. Para a intervenção realizada no centro comercial do Conjunto Jardim Maguari, em Belém (PA), o urbanismo tático foi adotado por diversos fatores, entre eles: ser de baixo custo, de forma a levar em consideração o caráter experimental do protótipo urbano e a falta de recursos para sua execução; de resposta rápida ao problema, uma vez que a dinâmica do espaço público é intensa e os problemas emergentes; por seu aspecto colaborativo, como forma de envolver a comunidade no processo de intervenção e, assim, estimular o senso de pertencimento ao local.

As ações colaborativas são desejáveis para a ativação e conservação do espaço público por priorizar a perspectiva dos usuários no processo de idealização do projeto urbanístico como forma de torná-lo mais democrático. Para Carr et al (1995), a elaboração de uma proposta de intervenção para um espaço público deve considerar as necessidades, direitos, significados e conexões estabelecidas com o lugar. Nesse processo, a participação do usuário deve ser valorizada.

Com o objetivo de explorar o conceito de urbanismo tático a partir da aplicação em uma situação real, este artigo apresenta os resultados de uma pesquisa experimental realizada no centro comercial do Conjunto Jardim Maguari, em Belém (PA). O artigo apresenta o processo, métodos e resultados da intervenção urbana, que teve como objetivo geral reconectar as pessoas ao espaço público a partir do método pesquisa-ação que, em síntese, "estabelece uma ponte entre teoria e prática, ao promover, simultaneamente a produção de conhecimento e a intervenção na realidade prática" (SANTOS; DAVEL, 2018, p. 727 e 728). Portanto, busca-se, em conjunto com o método adotado, fortalecer a relação com a comunidade e aprofundar 
ou direcionar o conhecimento prático alinhado ao saber teórico para potencializar os resultados da intervenção urbana.

\section{Resgate histórico e consolidação do centro comercial do Jardim Maguari housing complex: conflitos e concordâncias}

\section{A participação popular na história da cidade de Belém}

Fundada em 1616 sob terras indígenas, a cidade de Belém tem sua história marcada por uma ocupação territorial com pouco apreço pelos recursos naturais e por conflitos sociais derivados da imposição dos interesses dos grupos hegemônicos (CARDOSO et al, 2016; PORTELA, 2005).

Portela (2005) comenta que a ocupação do espaço urbano na região amazônica e, em especial, Belém, teve, desde o período colonial, forte determinação econômica pelas políticas nacionais e internacionais, que objetivavam o desenvolvimento capitalista na região, em um cenário que combinou modernização e exclusão social norteados pelas práticas patrimonialistas e clientelistas.

Marcada pelos ciclos econômicos, como as atividades extrativistas e o boom da borracha na Amazônia, a ocupação territorial acentuou uma urbanização associada aos interesses das elites econômicas regionais e pouco relacionada com as características específicas do território e com as necessidades dos grupos sociais mais vulneráveis. Esse processo também impulsionou a moradia precária, em um planejamento urbano deficiente na aplicação dos direitos sociais, o que agravou os conflitos entre classes, o que, por outro lado, fomentou a emergência da organização popular em busca dos seus direitos. (CARDOSO et al, 2016; RIBEIRO, 2013; PORTELA, 2005).

Essas movimentações populares, bastante relacionadas no seu surgimento nos anos 1950-60 aos sindicados e movimentos dos trabalhadores, foram reprimidas com o golpe militar em 1964, e atuaram de forma clandestina até o retorno da democracia em 1985. Várias manifestações populares se fizeram presentes na campanha "Diretas Já", até a promulgação da Constituição Federal de 1988 e nos anos que se seguiram.

Embora a participação popular tenha aumentado principalmente a partir dos anos 1970 em Belém (PORTELA, 2005), ainda tem grande força, no planejamento urbano e nas políticas públicas, as práticas clientelistas e patrimonialistas, com pouca ou nenhuma participação popular nas decisões políticas, além dos escassos recursos para as questões sociais. Nesse sentido, estratégias de urbanismo tático como intervenções urbanas colaborativas tem grande importância, tanto no envolvimento da população como agentes da ação, quanto na consolidação de soluções com poucos recursos.

\section{Formação e consolidação espacial do centro comercial}

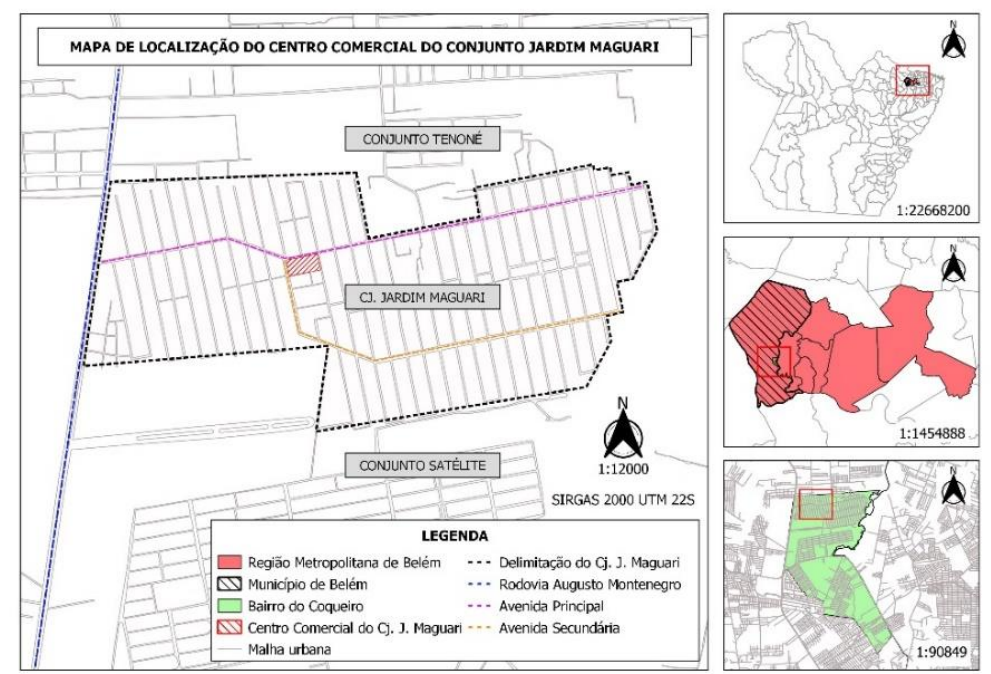

Figura 1: Mapa de localização do centro comercial do Conjunto Jardim Maguari, Belém (PA). Fonte: BELÉM (2008); CODEM (2020). Elaborado por: Kayan Freitas de Araújo.

O centro comercial (Figura 1) de estudo neste artigo se localiza na Av. Principal do Conjunto Jardim Maguari, entre a Av. Secundária e Alameda 13 B, bairro do Coqueiro, Belém (PA). A região, contida na Zona do Ambiente Urbano 4 (ZAU 4), caracteriza-se pelo uso predominantemente residencial, infraestrutura urbana não consolidada, deficiência de equipamentos urbanos comunitários e atividades econômicas dispersas (BELÉM, 2008).

Em funcionamento desde a década de 1980, data afirmada em entrevistas com alguns dos primeiros moradores do conjunto habitacional, o centro comercial integra 
Kayan Araújo, Verônica Garcia Donoso e Luan Rodrigo dos Santos Cavaleiro

Processo de intervenção urbana colaborativa no centro comercial do Conjunto Jardim Maguari, Belém (PA)

a lista de equipamentos urbanos previstos no plano urbanístico ${ }^{1}$ desenvolvido pela construtora ENEL Engenharia S/A para o Conjunto Jardim Maguari, com a pretensão de atender cerca de 1.700 famílias, a princípio - número de unidades habitacionais loteadas formalmente pela construtora e comercializadas em conjunto com Associações de Empréstimo e Poupança $\left(\mathrm{APEs}^{2}\right)$, segundo informações coletadas em entrevistas com o sócio proprietário da empresa ENEL Engenharia S/A e funcionários das APEs (Socilar Crédito Imobiliário e Vivenda Poupança e Empréstimos).

A constituição da história cronológica do centro comercial é um resgate baseado na memória viva de moradores que residem na região em intervalos de tempo diferentes, mas que recordam de acontecimentos pontuais que contribuíram para a configuração espacial atual do equipamento público. Zeneide Araújo ${ }^{3}, 77$ anos, pensionista e residente há 36 anos no conjunto, descreve fisicamente o equipamento urbano como sendo composto por blocos comerciais grandes dispostos de forma linear, onde encontravam açougue, farmácias, bazar, bar, hortifruti, mercearia, entre outras atividades econômicas; também nesse espaço eram negociadas as unidades habitacionais do conjunto que ainda não haviam sido vendidas.

Ao passar dos anos, sucessivas ocupações irregulares (Figura 2) suprimiram parte da área livre do centro comercial para a instalação de novos pontos comerciais. Em um primeiro momento, na década de 1980, foram loteadas as áreas mais próximas aos eixos viários principais (Av. Principal e Av. Secundária), onde foram construídos pontos provisórios em madeira, refeitos posteriormente em alvenaria para comercialização, de acordo com outro morador que preferiu não se identificar. Esse episódio possibilitou uma maior diversidade de atividades econômicas e serviços, o que pode ter vindo a aumentar o fluxo de consumidores no centro comercial e a estimular a economia local, de forma a valorizar comercialmente o entorno imediato. No final da década de 1990, as áreas centrais do centro comercial também foram ocupadas. Em conversa com uma antiga comerciante do local, Marlise Silva ${ }^{4}, 53$ anos, que

${ }^{1}$ Conjunto habitacional horizontal projetado na década de 1970, localizado na Rodovia Augusto Montenegro, Belém (PA).

${ }^{2}$ Instituição financeira autorizada a funcionar pelo Banco Central, de forma a atuar na captação de poupança e financiamentos imobiliários (BRASIL, 1966).

${ }^{3}$ Entrevista concedida por ARAÚJO, Zeneide R. Entrevista I. [out. 2020]. Entrevistador: Kayan Freitas de Araújo. Belém, 2020. 1 arquivo .mp3 (17 min.). trabalhou entre 1995 e 2001 com "jogo do bicho 5", é possível compreender o impacto no equipamento urbano:

Eu trabalhava com jogo do bicho e fui obrigada a vender meu box porque quando invadiram lá, invadiram vários boxes também, o meu, da minha irmã e de outras pessoas. Fiquei com medo de ficar lá e vendi, o movimento também tava diminuindo e vendi antes que não tivesse mais valor, aí em 2001 eu vendi, foi até melhor porque lá não é mais como antes (Informação verbal).

A ocupação mais recente produziu mais ambientes hostis, insalubres e de suporte para violência urbana. Retrata-se o ambiente noturno como propício ao consumo de drogas ilícitas, furtos, roubos, depósito de resíduos sólidos (estes em período diurno também), de associação a banheiros públicos, principalmente pela inatividade do comércio nesse período; consequentemente, esse fato diminui consideravelmente o fluxo de pessoas no local, de modo a vulnerabilizá-lo.

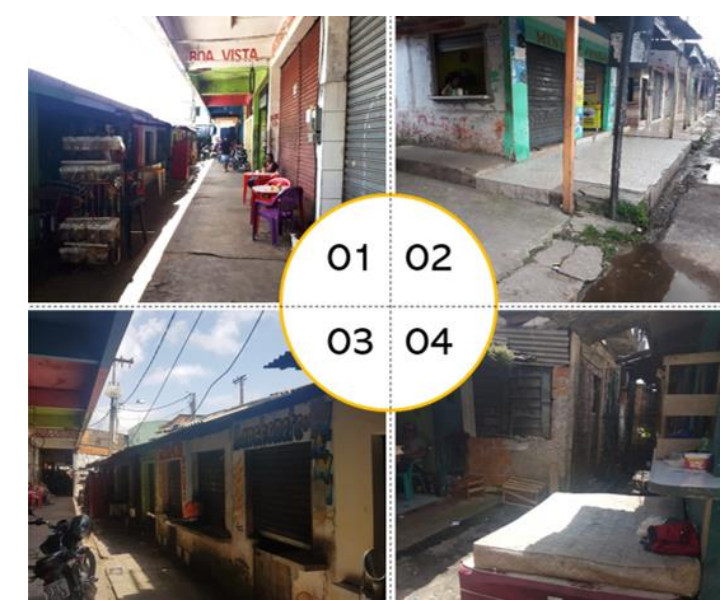

Figura 2: Instalações físicas em linha temporal: 01) primeiros boxes comerciais; 02) Primeira ocupação irregular; 03) Última ocupação irregular; 04) Espaços residuais decorrentes da última ocupação irregular. Fonte: Acervo dos autores.

${ }^{4}$ Entrevista concedida por SILVA, Marlise S. Entrevista II. [out. 2020]. Entrevistador: Kayan Freitas de Araújo. Belém, 2020. 1 arquivo .mp3 (9 min.).

${ }^{5}$ Sistema de loteria que consiste em apostas em números representados por animais, vinte e cinco no total. 
Kayan Araújo, Verônica Garcia Donoso e Luan Rodrigo dos Santos Cavaleiro

\section{A depreciação do centro comercial: principais provocadores}

Os equipamentos comunitários desempenham importante função para o equilíbrio social, político, cultural e psicológico de uma população, pois funcionam como fator de escape das tensões geradas pela vida contemporânea em comunidade (COUTO, 1981 apud ROMANINI, 2012, p. 60) ${ }^{6}$.

Para Moraes, Goudard e Oliveira (2008), a relevância dos equipamentos urbanos comunitários no ambiente urbano se justifica pela relação direta e proporcional à qualidade do espaço público e de vida da população. Define-se, portanto, os equipamentos comunitários como elementos físicos de influência no desenvolvimento urbano e econômico de uma região. A NBR 9284 (1989, p. 1) define esse elemento urbano da seguinte forma: são "todos os bens públicos ou privados, de utilidade pública, destinados à prestação de serviços necessários ao funcionamento da cidade, implantados mediante autorização do poder público em espaços públicos ou privados".

Em aspectos gerais, "consideram-se comunitários os equipamentos públicos de educação, cultura, saúde, lazer e similares" (BRASIL, 1979, on-line). Santos (1988) afirma que esses equipamentos deveriam ser programados à demanda correspondente, de acordo com sua classificação, atribuídos a sítios específicos e distribuídos de acordo com o raio de abrangência e a escala considerada: cidade, bairro e vizinhança. Já para Arfelli (2004), os equipamentos comunitários são aqueles que servem a comunidade:

Enquanto que os equipamentos urbanos integram a infra-estrutura básica necessária a expansão da cidade, destinados portanto a dar suporte ao seu crescimento e a proporcionar condições dignas de habitabilidade, os equipamentos comunitários são aqueles dos quais valerá o poder público para servir a comunidade que ocupará os lotes criados pelo parcelamento urbano, nas áreas de educação, saúde, assistência social, esportes, cultura, lazer etc. (ARFELLI, 2004, p. 23).

O centro comercial do Conjunto Jardim Maguari (Figura 3) é designado por alguns moradores por 'feira' ou, simplesmente, 'centro'. Este equipamento urbano pode ser melhor entendido a partir da definição de termos relacionados a este: feira, mercado e centro comercial. No dicionário online Michaelis, a expressão 'feira' remete à lugar público e descoberto, destinado a reunião de pessoas para venda e compra de mercadorias periodicamente, o que não corresponde as características do local, apesar de existirem poucas estruturas móveis e de uso temporário; a expressão 'mercado' sugere a comercialização de algumas mercadorias em espaço coberto ou ao ar livre; e o termo 'centro comercial' se refere a concentração de atividades comerciais em uma região, independentemente da existência de uma estrutura física ou delimitação pré determinada.

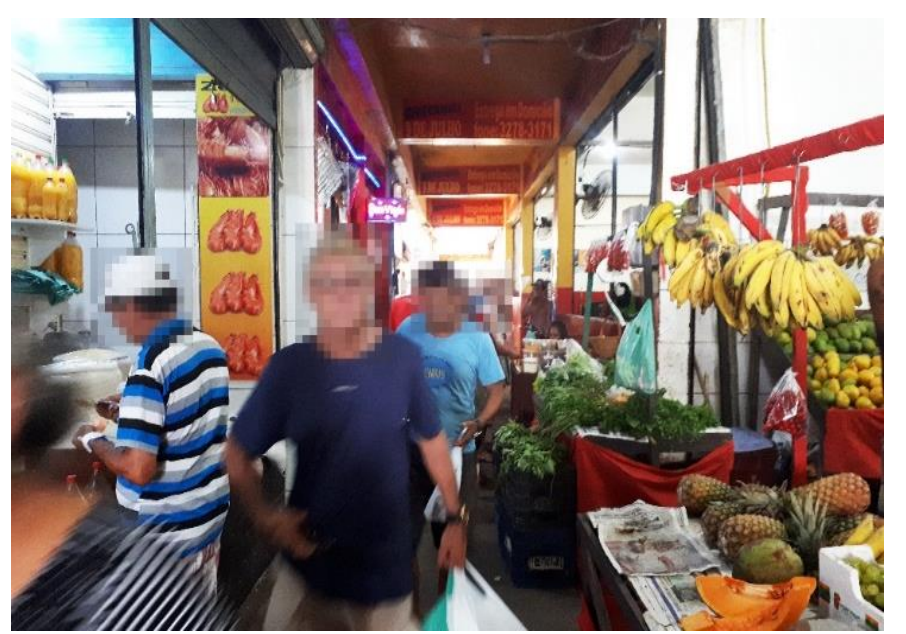

Figura 3: Circulação principal do Conjunto Jardim Maguari. Fonte: Acervo dos autores.

Os equipamentos urbanos detêm um raio de abrangência ou possuem critérios que induzem sua localização no sítio urbano como a frequência de uso, escala do território ou demanda local (SANTOS, 1988; NEVES, 2014). Em mercados de pequeno porte, Santos (1988, p. 159) sustenta a ideia de que devem "se localizar em centros de bairro, gerando aglomerações e atraindo outras atividades e equipamentos urbanos para sua vizinhança (comércio privado, igreja, praça, telefone público, banca de jornais)". Guimarães (2004) defende que centros comerciais para populações de até 10.000 (dez mil) habitantes podem distar em até $2.400 \mathrm{~m}$ das residências. No

${ }^{6}$ COUTO, Sérgio A. Frazão. Manual teórico e prático do parcelamento urbano. Rio de Janeiro: Forense, 1981. 
Conjunto Jardim Maguari, com base em todos esses parâmetros, o estudo de caso se encontra adequado ao deslocamento saudável do pedestre ou outro usuário e impulsiona o surgimento de novas atividades comerciais nas imediações, conforme a análise de uso e ocupação do solo, onde constata-se a influência do equipamento urbano.

A facilidade de acesso ou a proximidade, deixavam pouco a pouco de ser o grande fator de atração da população, pois esta, estava agora disposta a cobrir maiores distâncias, permanecer mais tempo, e aproveitar as melhores vantagens, tanto através das compras comparadas, como no uso fruto das novas atividades de lazer (VARGAS, 1992, p. 273).

Gehl (2013) afirma que serviços e espaços públicos devem estar localizados a uma distância confortável para o deslocamento a pé. Para o autor, a caminhabilidade pode proporcionar melhores condições de saúde das pessoas e fomentar o comércio e atividades de turismo na cidade. Campos Filho (2010) defende que as atividades comerciais de uso frequente da população, como as prestadas no Conjunto Jardim Maguari, devem se localizar perto das residências, enquanto as de menor frequência, mais distantes.

Para a leitura urbana do equipamento público, associa-se o método de observação direta a diálogos com comerciantes e usuários do centro comercial como metodologias de pesquisa para obtenção de dados que permitam diagnosticar, a partir de uma percepção técnica, os problemas urbanos vinculados a dinâmica local.

Observa-se que as atividades econômicas no Conjunto Jardim Maguari exercem grande influência na dinâmica urbana e na relação das pessoas com os espaços públicos. O comércio local desempenha papel fundamental no comportamento dos moradores, valoração atribuída a diversidade de atividades comerciais e de serviço de consumo frequente da população como mercados, salões de beleza, panificadoras, bares e restaurantes, que funcionam em todos os turnos, de forma a manter os espaços públicos com fluxo constante, mas que tem sua operação prejudicada principalmente por dois fatores principais: questões relativas a falta de manutenção do espaço e ao uso e ocupação.

A falta de manutenção e de readequação urbana em relação ao contexto atual agravam problemas na estrutura urbana do espaço público que envolvem questões de acessibilidade espacial, mobilidade urbana e funcionalidade, questões relacionadas diretamente ao uso e ocupação do ambiente e que podem culminar na diminuição da demanda de usuários do equipamento urbano, acidentes (principalmente, quedas e colisões entre usuários: ciclistas, motociclistas e pedestres) e na vulnerabilidade deste usuário a roubos, furtos, ou ações mais agressivas. Gehl (2013, p. 91) afirma que, "sentir-se seguro é crucial para que as pessoas abracem o espaço urbano. Em geral, a vida e as próprias pessoas tornam a cidade mais convidativa e segura, seja em termos de segurança percebida ou vivenciada".

Nos últimos anos, outros comércios, mais modernos e diversificados, surgiram nas imediações do estudo de caso e, de certa forma, ameaçam a economia local, uma vez que as pessoas buscam cada vez mais segurança e conforto. São exemplos: o Parque Shopping Belém, o Mix Matheus Atacarejo e o Supermercado Líder, localizados em bairros próximos.

Nota-se a falta de senso de coletividade no ambiente entre os comerciantes que, diariamente, depositam resíduos sólidos na circulação de pedestres ou na pista de rolamento, de forma a criar condições propícias ao desenvolvimento de roedores e insetos não desejáveis. A infraestrutura precária, principalmente na parte ocupada irregularmente, oferece riscos à segurança do usuário por gerar espaços mal iluminados e impermeáveis visualmente; a presença ou ausência de mobiliário urbano, como bancos, lixeiras e placas de identificação, a exemplo, influenciam na permanência, conservação e orientação espacial no espaço público, respectivamente. Para Vargas e Castilho (2006), a deterioração de um espaço está relacionada ao desgaste ou comprometimento da estrutura física, enquanto o conceito de degradação à perda de valor, marginalização. Ambos corroboram à perda de função.

O calçamento (Figura 4), deteriorado e com medidas incompatíveis ao fluxo de pessoas e de acessibilidade espacial, dificulta o deslocamento de pedestres e, principalmente, de pessoas com deficiência física ou mobilidade reduzida. Entretanto, além das condições físicas descritas acima, pedestres compartilham o espaço com ciclistas e motociclistas, usuários que buscam praticidade em seu deslocamento na região, de forma aumentar o risco de acidentes provenientes do conflito espacial entre esses usuários no centro comercial. 
Kayan Araújo, Verônica Garcia Donoso e Luan Rodrigo dos Santos Cavaleiro

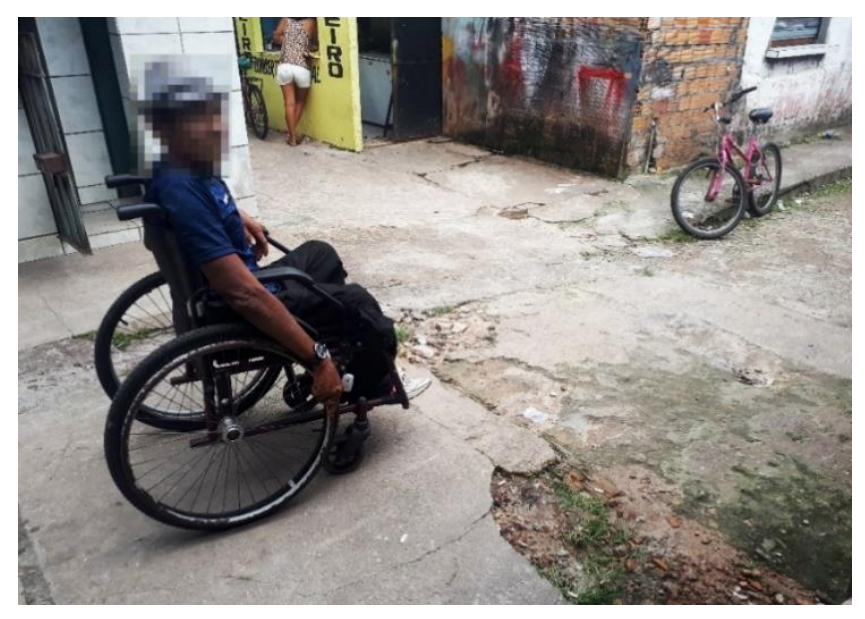

Figura 4: Condição física do calçamento da circulação principal do centro comercial do Conjunto Jardim Maguari. Fonte: Acervo dos autores.

A relação da vizinhança com o equipamento urbano sofre desgaste gradual decorrente de fatores internos: falta de manutenção, modernização e conservação do ambiente limpo, assim como outros de menor impacto; e de fatores externos: instalação de grandes redes de supermercados e de shoppings centers. Os resultados são constatados em diálogos com os comerciantes: acidentes constantes, queda no fluxo de consumidores, aumento da periculosidade do local e limitações de acesso físico por usuários deficientes físicos ou com mobilidade reduzida. Por outro lado, percebe-se a ânsia em transformar o espaço por ser o ambiente de trabalho, lar ou espaço de lazer entre os usuários, contraposta pela desunião entre os comerciantes e baixos recursos financeiros para a promoção de um ambiente social com melhor qualidade para a população. Eliane Gomes $^{7}, 54$ anos, comerciante a mais de duas décadas no centro comercial, defende o espaço: "eu gosto daqui, é bom pra trabalhar, tem o pessoal que a gente já conhece, só tá sujo e mal cuidado, é só cada um cuidar melhor do seu box"; o depoimento esboça um sentimento de pertencimento entre a entrevistada e o equipamento urbano. Para Lestinge (2004, p. 40, grifo nosso), o pertencimento remete a duas possibilidades:

${ }^{7}$ Entrevista concedida por GOMES, Eliane A. Entrevista III. [out. 2020]. Entrevistador: Kayan Freitas de Araújo. Belém, 2020. 1 arquivo .mp3 (14 min.).
A priori esse conceito - pertencimento - pode nos remeter a, pelo menos, duas possibilidades: uma vinculada ao sentimento por um espaço territorial, ligada, portanto, a uma realidade política, étnica, social e econômica, também conhecida como enraizamento; e outra, compreendida a partir do sentimento de inserção do sujeito sentir-se integrado a um todo maior, numa dimensão não apenas concreta, mas também abstrata e subjetiva.

No centro comercial, percebe-se uma relação de identificação e pertencimento principalmente entre comerciantes com o ambiente construído em questão, porém, o desgaste progressivo dessa relação pode ter influenciado ou sido motivador para o descuido com o espaço. Em contrapartida, a relação entre usuários e o ambiente construído é mais distante, isto é, observa-se um grau de dependência devido aos serviços ofertados, mas a ausência de uma ocupação a fins de lazer ou apropriação do equipamento urbano.

\section{Processo de intervenção urbana colaborativa: abordagens e resultados}

Entre agosto e dezembro de 2019, foi realizada a intervenção urbana no centro comercial do Conjunto Jardim Maguari, em condição de pesquisa experimental, na qual participaram voluntariamente estudantes de arquitetura e urbanismo da Faculdade Estácio de Belém, orientados pelo Prof. Me. Luan Rodrigo dos Santos cavaleiro, comerciantes e moradores do conjunto habitacional. Além desses, houve apoio operacional e financeiro de uma ex-vereadora do município de Belém por meio de recursos próprios e que atuou também como representante da população no bairro. A protótipo urbano desenvolvido é complemento ao trabalho de conclusão de curso de Kayan Freitas de Araújo, que buscou elaborar um plano de bairro para o Conjunto Jardim Maguari, no qual inseriu o urbanismo tático como estratégia para recuperação e apropriação de espaços livres do conjunto habitacional.

O objetivo foi estudar o protótipo urbano proposto e executado como metodologia alternativa à intervenção urbana e de gestão colaborativa e parcialmente independente do poder público. A partir do detalhamento do processo de intervenção urbana e dos resultados que serão apresentados, busca-se incitar reflexões acerca das possibilidades que vinculam a participatividade da população no processo de 
planejamento urbano e que provocam iniciativas populares para recuperação, transformação, ocupação e/ou apropriação do espaço de uso público.

A proposta de intervenção urbana colaborativa se concentra na entrada principal do centro comercial - pela Av. Principal, mas estende-se até o acesso pela Av. Secundária. Para o desenvolvimento do protótipo urbano, o processo de projeto considerou duas etapas fundamentais para a intervenção colaborativa: diálogos com a comunidade, etapa realizada por meio de entrevistas semiestruturadas e informais; e, planejamento e construção participativa, de forma a capacitar os voluntários para a produção autônoma e manutenção do mobiliário urbano projetado. Outras etapas são abordadas nos parágrafos seguintes, tais como: o levantamento físico, fotográfico e a observação direta do espaço, métodos que deram suporte para o estudo e planejamento no âmbito técnico.

Nenhuma intervenção urbana pode começar sem que os moradores intervenham no diagnóstico, e toda obra requer a opinião e a atividade dos usuários a fim de valorizar e qualificar sua manutenção, de modo a interpretar sua pós-ocupação. (MONTANER E MUXÍ, 2014, p. 219).

O processo de projeto (Quadro 1) considerou etapas fundamentais para a realização da intervenção urbana que colaboraram para a organização entre os membros da equipe e voluntários. O planejamento contribuiu também para uma visão geral do processo e domínio das etapas para que o objetivo final fosse alcançado. Lydon e Garcia (2015, p. 234) afirmam que "mesmo a intervenção mais leve requer algum planejamento. Isso inclui considerar o design FíSICO, MAS TAMBÉM ELEMENTO LOGÍSTICOS, COMO QUEM AJUDARÁ, QUANDO REALIZAR O PROJETO, COMO O PROJETO SERÁ financiado e quais materiais serão usados".

Lydon e Garcia (2015) orientam o uso da estrutura do design thinking - adaptação criativa, racional e empática de soluções ao contexto do problema (KELLEY; KELLEY, 2013), e listam cinco etapas utilizadas por urbanistas táticos correspondentes ao processo conhecido por problem-identification-to-project-response - algo próximo de 'identificação do problema como resposta ao projeto', são elas: 1) entender para quem você realmente está planejando ou projetando; 2) investigar e conhecer as causas dos problemas que precisam ser abordadas; 3 ) explorar as possíveis soluções ao problema definido; 4) elaborar proposta de projeto exequível, de baixo custo e de execução rápida; 5) executar e realizar a avaliação pós-ocupação do projeto a partir do método build-measure-learn - consiste em construir o protótipo, avaliar os impactos e a receptividade do projeto por análises periódicas e aprimorar a proposta a partir dos resultados obtidos.

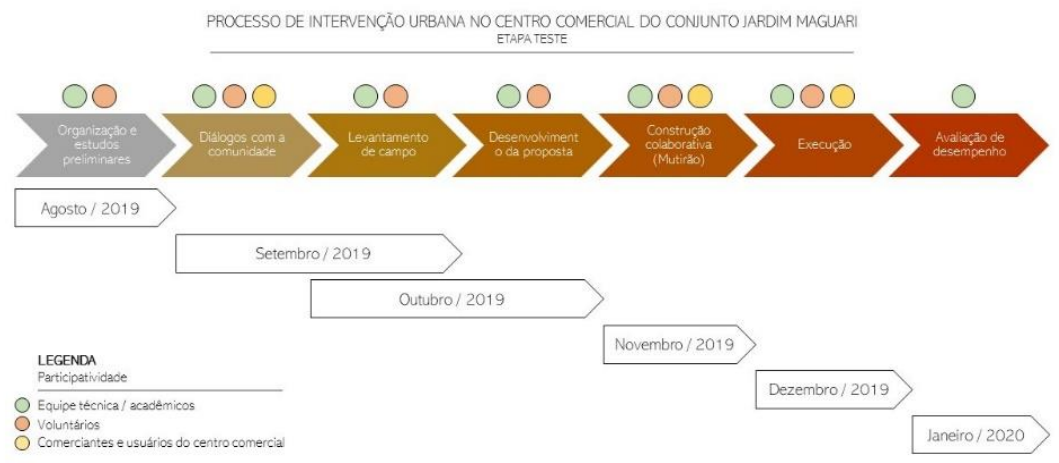

Quadro 1: Processo de intervenção urbana e cronograma de planejamento e ação. Fonte: Elaborado pelos autores.

O método build-measure-learn pode criar um vínculo entre a comunidade e o espaço, de forma a conscientizar a população de que é possível realizar mudanças. O processo se baseia nos resultados da realização da primeira intervenção, onde se pode remodelar a proposta inicial até esta se mostrar adequada ao contexto em que está sendo inserida; para isso, a fase de teste deve ser executada repetidamente até concluir que o projeto está apto a investimentos maiores, isto é, quando for possível cogitar a implementação de estruturas permanentes, naturalmente com maiores custos que estruturas efêmeras (LYDON; GARCIA, 2015).

Apropria-se do urbanismo tático para delinear as etapas do processo de intervenção por abarcar técnicas com resultados rápidos, de aspecto colaborativo, e considerar elementos construtivos de baixo custo, principalmente. Sendo assim, esclarece-se que a intervenção está associada a etapa de teste do protótipo urbano, em concordância com o processo build-measure-learn, referenciado por Lydon e Garcia (2015). Isto posto, as etapas concernentes à intervenção urbana são: 1) definição da área para intervenção; 2) diálogos com a comunidade; 3) levantamento de 
campo; 4) elaboração e desenvolvimento da proposta de intervenção; 5) mutirões de produção; 6) ações preliminares; 7) execução do projeto; 8) estudo pós ocupação do espaço público.

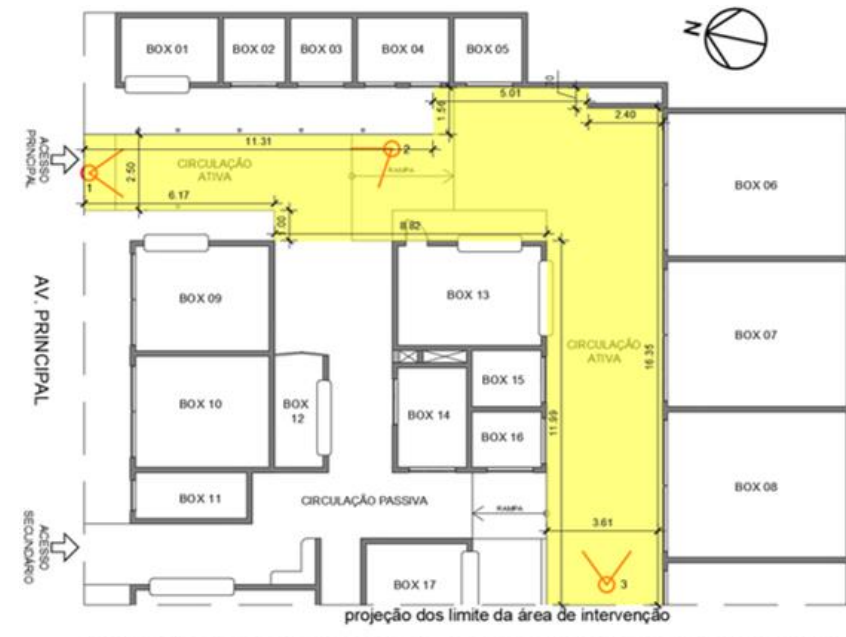

PLANTA BAIXA
ESC.: $1 / 200$

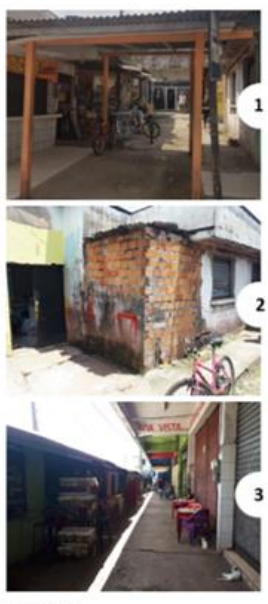

LEGENDA

$\square$ Área de intervenço

Figura 5: Delimitação da área para intervenção urbana no centro comercial do CJ. Jardim Maguari: estudo preliminar. Fonte: Acervo dos autores.

Definição da área para intervenção (Figura 5). Por meio de conversas informais com a direção do colégio Centro Educacional Vovó Paula (CEVP), localizado próximo ao centro comercial, levantou-se a possibilidade de unir forças com a comunidade para produzir uma intervenção urbana em pequena escala. Impulsionados pela precariedade, necessidade e impacto do equipamento urbano na vizinhança, iniciou-se a elaboração de um plano de ação para articular esta ideia inicial em conjunto ao Escritório Modelo de Arquitetura de interesse social (E+Estácio $)^{8}$.

Diálogo com a comunidade. Realizaram-se entrevistas semiestruturadas e informais com a comunidade com o objetivo de levantar dados para dar suporte no

${ }^{8}$ Projeto de extensão vinculado ao curso de Arquitetura e Urbanismo pela instituição de ensino superior Estácio de Belém, coordenado pelo Prof. Me. Luan Rodrigo dos Santos Cavaleiro. desenvolvimento do protótipo urbano. Com os resultados foi possível identificar alguns problemas urbanos provenientes da vivência no espaço público por esses usuários, a fim de propor soluções cabíveis considerando a metodologia de intervenção do urbanismo tático, isto é, de efeitos rápidos e de baixo custo, principalmente.

Levantamento de campo. Esta etapa foi realizada em dois momentos, sendo o primeiro reservado a levantar as medidas gerais e, assim, desenvolver a planta baixa da área de intervenção, concomitante ao levantamento fotográfico. Posteriormente, houve o retorno ao local para constatação das medidas levantadas e observação do espaço público para entender a dinâmica urbana sob perspectiva técnica. A confluência dos dados gerados nessa etapa possibilitou trabalhar dentro de uma área mais próxima do real, de modo a permitir o orçamento de materiais sem grandes desperdícios, a elaboração um plano de execução e a seleção dos materiais para uso no projeto. Essa etapa foi realizada em parceria com voluntários do curso de bacharelado em Arquitetura e Urbanismo da Faculdade Estácio de Belém.

Desenvolvimento da proposta de intervenção (Figura 6). Esta etapa foi orientada pelo E+Estácio e avaliada pela direção do CEVP e por representantes dos comerciantes do centro comercial. Nessa etapa foram estudados mobiliários urbanos de baixo custo produzidos a partir do reaproveitamento de materiais descartados por comerciantes do conjunto: pallets, garrafas pet, pneus de carro e caixotes. Também foi feito o layout da paginação de piso e determinadas as ações preliminares da intervenção. Portanto, para a fase teste, propôs-se ao centro comercial a instalação de três tipologias de floreiras (com pneus, pallets e caixotes), bancos de pallet $\mathrm{e}$ uma nova paginação de piso. 


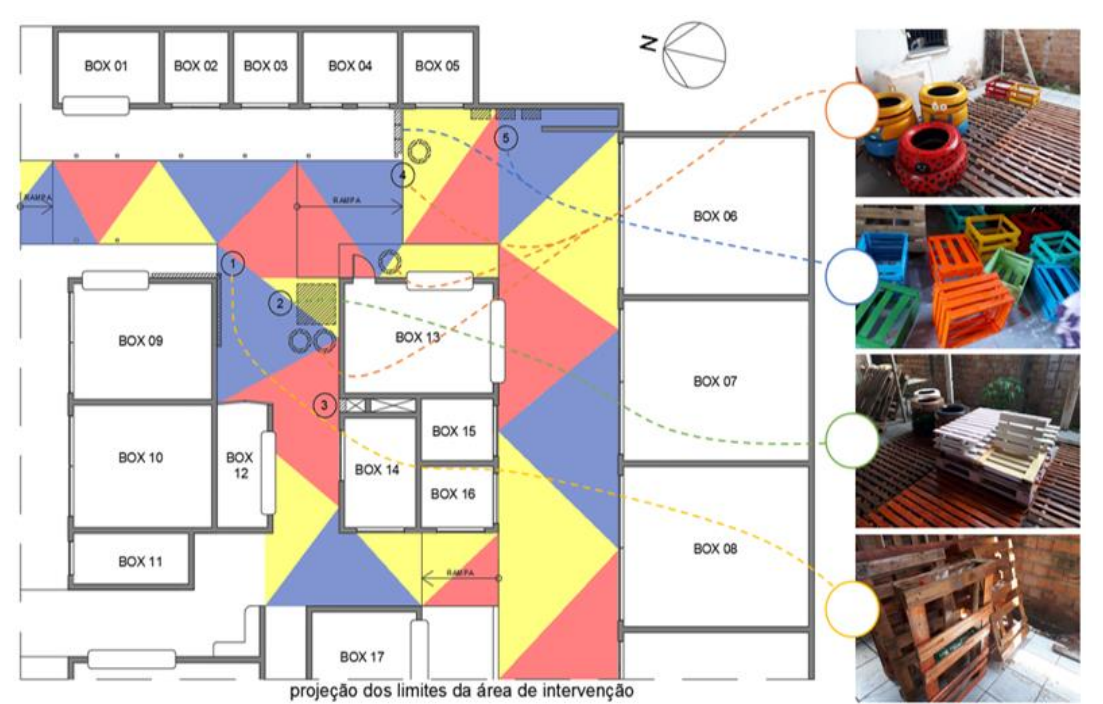

Figura 6: Layout da proposta de intervenção no centro comercial do Conjunto Jardim Maguari. Fonte: Acervo dos autores.

Mutirões. Essas ações aconteceram semanalmente, aos finais de semana, onde se reuniam a equipe do colégio CEVP, moradores e voluntários que se interessavam pelo projeto, especialmente do Grupo de Mulheres do Conjunto Maguari (GRUMA), cuja sede foi o local de produção dos mobiliários urbanos. Aconteceram cinco mutirões para produção do mobiliário urbano: o primeiro voltado à busca de materiais pelo Cj. Jardim Maguari e os demais dedicados à produção. Em geral, as reuniões se iniciavam às $9 \mathrm{~h}$ e se estendiam até as 22:00 horas, com o revezamento de voluntários.

As possibilidades de mobiliários eram discutidas e questionadas quanto à exequibilidade, haja vista as limitações: econômica, de equipamentos para a produção, disponibilidade da matéria-prima no entorno e tempo de produção. Esses encontros proporcionavam intercâmbio de conhecimento e experiências entre os voluntários, comunidade e a equipe de apoio técnico.

Ações preliminares. Para a execução do projeto foram necessários o nivelamento do calçamento da circulação ativa principal para melhorar as condições de caminhabilidade, realizado um mês antes por iniciativa da direção do colégio CEVP; a limpeza do centro comercial, realizada um dia antes da pintura do piso, onde ocorreu a remoção e destinação adequada de resíduos sólidos depositados no calçamento e a preparação do piso para pintura, um dia antes da execução.

Execução do protótipo urbano. Foram promovidos três mutirões noturnos (entre 21:00 horas e 5:00 horas), após o fechamento completo do comércio, com os mesmos colaboradores dos outros mutirões: os primeiros foram destinados à pintura do piso com base no layout proposto, e o último para instalação do mobiliário urbano. A entrega da intervenção aconteceu no dia 24 de dezembro, mas ainda sem todo o mobiliário urbano, pois, o espaço destinado aos bancos com pallet foi ocupado por materiais de construção de um dos comerciantes, inviabilizando que a proposta fosse entregue como planejado.

No decorrer do processo de intervenção houve também alguns conflitos que dificultaram a etapa de execução, como a falta de compreensão de minoria que, por não se interessar pela proposta, não respeitava a interdição parcial da circulação para pintura, mesmo sendo feita por trechos e com caminhos alternativos; além disso, o processo de pintura do piso foi constantemente interrompido por conta das chuvas, com médias pluviométricas sempre elevadas no mês dezembro. No entanto, alguns comerciantes e moradores também contribuíram nessa etapa da seguinte forma: mantinham acesos os pontos de luz, enquanto outros estendiam o horário de funcionamento dos seus estabelecimentos para não dispersar os fluxos de pessoas, proporcionando sensação de segurança.

\section{Ensaio de estudo pós ocupação do protótipo urbano}

A apresentação dos resultados obtidos a título de estudo do método de intervenção urbana colaborativa é feita por meio do estudo por observação direta e opinião pública, questionada por entrevistas com comerciantes e demais usuários após instalação do mobiliário urbano e da paginação de piso em três cenários que se destacaram visualmente na composição paisagística. Sendo assim, buscando analisar esses espaços intervindos por uma abordagem multimétodos, tem-se então: registros fotográficos cronológicos, evidenciando o antes e depois da intervenção; observação direta como método complementar e vivência do ambiente público como forma de ampliar a perspectiva do pesquisador sobre a dinâmica do lugar. 
A avaliação pós-ocupação é fundamental para compreender e acompanhar os resultados do ambiente urbano construído, de forma a prever e controlar os efeitos dessas ações no espaço público (ORNSTEIN; RÓMERO, 1992). A partir disso, pode-se readequar ou reproduzir propostas de intervenção a partir da identificação de falhas ou pontos positivos resultantes da pesquisa experimental em questão. Para este artigo, os procedimentos e métodos que auxiliam no estudo pós ocupação não são aprofundados ou utilizados de forma complexa, pois o estudo é produzido após um mês a entrega da intervenção, sendo necessário retornos periódicos para a conclusão da avaliação. Portanto, apresenta-se resultados obtidos e que podem ser mutáveis com o passar do tempo.

Cenário 1 (Figura 7). Refere-se a uma área ociosa utilizada no período noturno como banheiro público. Gehl (2013) defende que o espaço público em sua disposição, mobiliários e proporção pode influenciar comportamentos, sendo assim, se atribuirmos outro valor ou funcionalidade a esse lugar, as pessoas podem vir a entendê-lo de outra forma, mudando seus hábitos e a relação com o espaço público gradualmente.

Após a instalação do mobiliário se observou que a frequência de pessoas que o utilizam como banheiro público diminuiu, e a ambiência do restaurante também se favoreceu desse resultado, conforme um dos entrevistados:

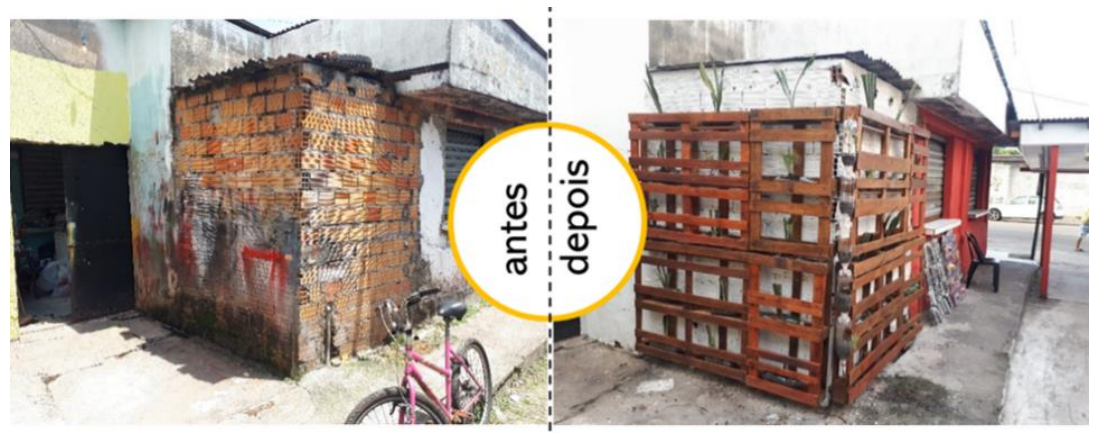

Figura 7: Fachada de restaurante localizado na esquina da entrada principal do centro comercial do Conjunto Jardim Maguari - antes e depois da intervenção urbana. Fonte: Acervo dos autores.

${ }^{9}$ Entrevista concedida por MEDEIROS, João G. Entrevista IV. [jan. 2020]. Entrevistador: Kayan Freitas de Araújo. Belém, 2020. 1 arquivo. mp3 (15 min.).
Bom, pra mim foi muito bom esse trabalho, creio que não só pra mim, mas pra todos. Agora quanto a mijadeira, isso vai depender da consciência do povo [...]. Mas creio que deu uma melhorada ali, mas continua ainda fazendo a mesma conduta que fazia, mas melhorou (Informação verbal) ${ }^{9}$.

Cenário 2 (Figura 8). Figura como ponto de fuga para transeuntes que circulam pela via principal do centro comercial, lugar com potencial para construção de um ponto referencial atrativo e de identificação do espaço. Anteriormente, a fachada era revestida por propagandas comerciais e apresentava deterioração na estrutura física; após a intervenção, o espaço estimulou a percepção sensorial das pessoas por sua composição baseada em cores vibrantes e no reaproveitamento de caixotes de madeira, associada a nichos para instalação de um jardim vertical.

O propósito da revitalização pontual nessa fachada é a ativação gradual dessa região por atividades que acontecem esporadicamente no centro comercial como mesas de jogo, e uma possível integração do espaço a atividades econômicas, isto é, utilização do espaço como extensão para bares e restaurantes, o que Jacobs (2011) afirma contribuir para a vitalidade do ambiente público, de forma a influenciar na sensação de segurança por parte do usuário. Em geral, tem-se o propósito de fomentar o comércio local e sustentar uma ideia de espaço público ocupado e seguro.

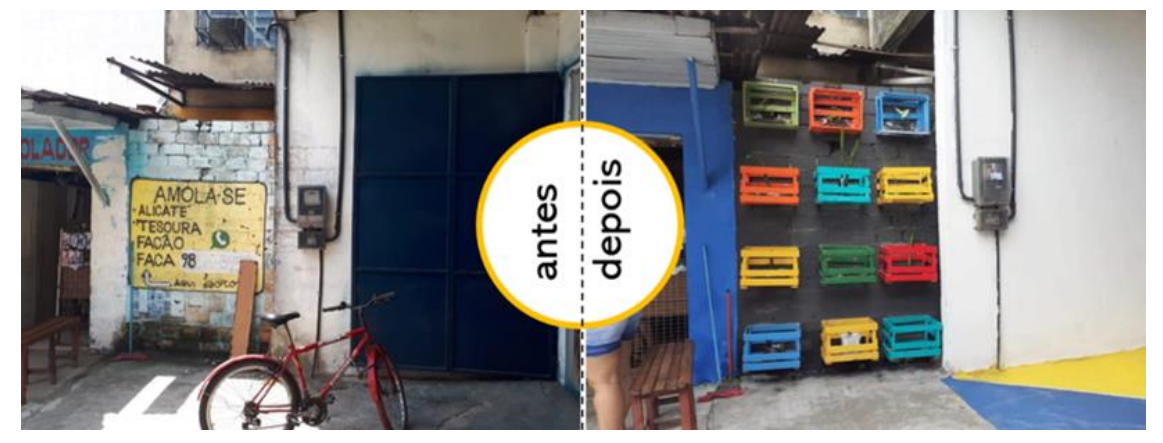

Figura 8: Fachada inativa localizada na entrada principal do centro comercial do Conjunto Jardim Maguari - antes e depois da intervenção urbana. Fonte: Acervo dos autores. 
Cenário 3 (Figura 9). Refere-se a paginação de piso proposto para a circulação principal do centro comercial e a revitalização do revestimento de fachada de alguns pontos comerciais. O design geométrico composto por três cores, amarelo, vermeIho e azul, corresponde a uma alternativa de rápida execução pela equipe envolvida devido ao intervalo de tempo curto para intervir no espaço público, uma vez que os fluxos de usuários são intensos durante o dia.

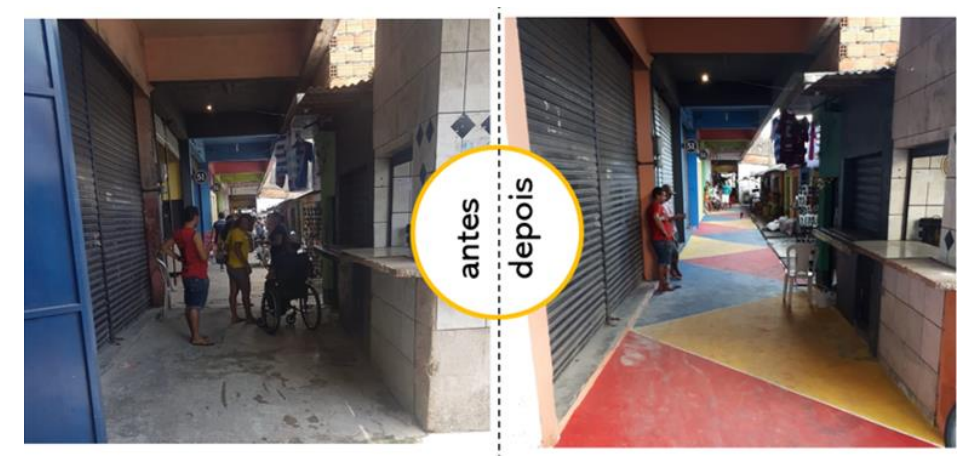

Figura 9: Circulação principal do centro comercial do Conjunto Jardim Maguari - antes e depois da intervenção urbana. Fonte: Acervo dos autores.

O impacto visual provocado pela repaginação do piso explicita as transformações urbanas possíveis com poucos recursos e viáveis para a região; a limpeza, organização e o aspecto estético servem de atrativo para estimular a conservação do centro comercial pelos comerciantes, entre outras pessoas que possam se identificar e cuidar do espaço também.

A Organização Mundial da Saúde (OMS) define saúde como um estado de completo bem-estar físico, mental e social [...]. As ruas urbanas fornecem a base para experiências cotidianas e devem, portanto, ser desenhadas para favorecer a saúde humana e o bem-estar de todas as pessoas (GDCl; NACTO, 2018, p. 12).

\section{Espaços públicos construídos a muitas mãos: a multiplicação de práticas} colaborativas na vizinhança

Em vista ao apresentado neste artigo, a iniciativa de intervenção urbana colaborativa compõe um processo de reconstrução social em relação ao ambiente público, sem desconsiderar os aspectos indissociáveis do processo de planejamento participativo; trata-se de intervenção que possibilita uma autorrevisão de comportamentos ou hábitos que, discretamente, deterioram e degradam o espaço de convívio comunitário e, consequentemente, afetam a dinâmica da cidade; como comenta Gehl (2013), molda-se a cidade para que ela possa nos moldar.

Tornar lugares habitáveis pode ser significar reconhecer esse mesmo lugar como parte indissociável da rotina de indivíduo, uma extensão de seus lares, comércios ou serviços. Gehl (2004) reitera que a participatividade é importante nessa construção, pois contribui para o autoreconhecimento do ambiente construído, lugar de intercâmbio intersocial.

Gehl (2004, p. 69) afirma que "a área que o indivíduo percebe como pertencente à habitação, o entorno residencial, pode estender-se muito além da habitação real. Isso em si pode dar como resultado uma maior utilização dos espaços públicos". Com base no estudo de caso, percebe-se que pequenas ações colaborativas podem ter influência significativa no entorno imediato e corresponder às expectativas dos autores em curto espaço de tempo, de forma também a fazer parte de um processo de construção e resultados gradativos.

Isto posto, é possível constatar a multiplicação de práticas colaborativas em outros espaços públicos do Conjunto Jardim Maguari após a implantação deste primeiro protótipo urbano como na Alameda $20 \mathrm{C}$ e $14 \mathrm{C}$, localizadas na Av. Secundária; e também no bairro contíguo, Tenoné. É importante frisar que mesmo antes da intervenção já haviam registros de outras práticas colaborativas como na Al. 11 B e próximo à entrada do conjunto habitacional. Nessa perspectiva, o urbanismo tático cumpre um dos seus objetivos: de conscientizar e estimular ações colaborativas por meio de intervenções práticas, em menor escala e de baixo custo.

A cooperação entre o corpo técnico (arquitetos e urbanistas/estudantes) e a comunidade contribuiu na revisão da percepção do espaço comunitário e da amplitude de alternativas para intervenção/adequação do ambiente público ao encontro das necessidades e desejos da comunidade. A participação de todos os grupos sociais (homens, mulheres, adolescentes, crianças, idosos etc.) se faz importante na produção de um espaço plural e funcional. 
Kayan Araújo, Verônica Garcia Donoso e Luan Rodrigo dos Santos Cavaleiro

Processo de intervenção urbana colaborativa no centro comercial do Conjunto Jardim Maguari, Belém (PA)

"A participação e construção colaborativa de espaços urbanos objetivam atendimento às demandas comunitárias bem como ao caráter técnico exigido pelos órgãos de controle e planejamento da cidade. A conexão dos atores que atuam no processo de construção urbana se faz eficiente quando proporciona a abertura aos interesses e necessidades diversos, empoderando efetivamente os usuários do espaço como parte ativa no processo de transformação. Tais usuários, ao estarem inseridos nas atividades decisórias, sentem-se reconhecidos, contemplados e integrantes da comunidade" (ARAÚJO ET AL, 2019, p. 76).

A participatividade foi, ao mesmo tempo, uma preocupação e um desejo para esse projeto urbano. Buscar alternativas para incluir o público alvo no processo foi uma ação com um desempenho abaixo das expectativas iniciais devido ao curto espaço de tempo para planejamento e execução. Apesar de alguns voluntários que contribuíram ativamente em quase todo o processo serem moradores ou usuários do centro comercial, sentiu-se no resultado final a falta da colaboração maior de comerciantes do local, que pode ter sido motivada pela descrença em práticas colaborativas e com pouco investimento, ou por ser ano eleitoral e a financiadora do projeto de intervenção ser uma representante política.

O intuito deste artigo ao apresentar a intervenção urbana no centro comercial do Conjunto Jardim Maguari, em Belém, é contribuir para pesquisas científicas que buscam sustentar a defesa ou análise crítica do urbanismo tático como método alternativo e participativo, baseado na análise de estudos de caso. A partir desses resultados é possível perceber o impacto no entorno imediato da área de intervenção e estudar as aderências e deslizamentos do processo, aplicado a esse caso, para aprimoramento das técnicas e abordagens para a reformulação do projeto piloto e estruturação de uma proposta definitiva mais consistente, coesa e funcional.

\section{Referências}

ABNT, Associação Brasileira de Normas Técnicas. NBR 9284/1986: Equipamento Urbano. Rio de Janeiro, 1986.

AHMAD, Sarah N. Collaborative Planning, Governance and resistance: institutional provision in Lahore. Pakistan Journal of urban affairs. Lahore, Pakistan, v. 1, n. 6, p. 23-39, out. 2017.

ALEX, Sun. Projeto da Praça: Convívio e exclusão no espaço público. São Paulo. Editora SENAC, 2008, 291p.
ARAÚJO, Luiz Eduardo Sarmento; BOMTEMPO, Mariana Roberti.; MELO, Daniel Bruno Vieira de; COELHO, Manuela de Carvalho; MARINHO, Sandra Maria França. Assistência técnica em urbanismo e habitação de interesse social: anotações de imersão da equipe técnica do CODHAB nas periferias do Distrito Federal - 20152018. Brasília: IAB-DF, 2019, 700 p.

ARFELLI, Amauri Chaves. Áreas verdes e de lazer: considerações para sua compreensão e definição na atividade urbanística de parcelamento do solo. Revista de Direito Ambiental. São Paulo, v. 9, n. 33, p. 45, jan/mar 2004.

BELÉM. Lei no $\mathbf{8 . 6 5 5}$, de $\mathbf{3 0}$ de julho de 2008. Dispõe sobre o Plano Diretor do Munícipio de Belém, e dá outras providências. Belém: Câmara Municipal, [2008]. Disponível em: http://www.belem.pa.gov.br/planodiretor/Plano_diretor_atual/Lei_N865508_plano_diretor.pdf. Acesso em: 20 jan. 2020.

BRASIL. Decreto-Lei no 70, de 21 de novembro de 1966. Autoriza o funcionamento de associações de poupança e empréstimo, institui a cédula hipotecária e dá outras providências. Brasília: Subchefia para assuntos jurídicos da presidência da república, [1966]. Disponível em: http://www.planalto.gov.br/ccivil_03/decretolei/del0070-66.htm. Acesso em: 31 jan. 2020.

BRASIL. Lei no 6.766, de 19 de dezembro de 1979. dispõe sobre o parcelamento do solo urbano e dá outras providências. Brasília, [1979]. Disponível em: http://www.planalto.gov.br/ccivil_03/leis/6766.htm. Acesso em: 10 mar. 2020.

CAMPOS FILHO, C. M. Reinvente seu bairro: caminhos para você participar do planejamento de sua cidade. $2^{\mathrm{a}}$ ed. São Paulo: Editora 34, 2010, 224 p.

CARDOSO, A. C. D.; LIMA, J. J. F.; VENTURA NETO, R.; RODRIGUES, R. M.; XIMENES, J. P.; GOMES, T. do V. Forma urbana de Belém e seus desdobramentos para a formação de um sistema de espaços livres acessível à população. Paisagem e Ambiente, [S. I.], n. 37, p. 11-34, 2016. DOI: 10.11606/issn.2359-5361.v0i37p1134. Disponível em: https://www.revistas.usp.br/paam/article/view/101362. Acesso em: 2 maio. 2021.

CARR; Stephen; FRANCIS, Mark; RIVLIN, Leanne G.; STONE, Andrew M. Public Space. Cambridge: Cambridge University Press, 1995.

GEHL, Jan. Cidades para pessoas. $1^{\text {a }}$ ed. São Paulo: Perspectiva, 2013, 280 p. 
GEHL, Jan. La humanización del espacio urbano. Barcelona: Editorial Reverté, 2004.

Global Designing Cities Initiative (GDCl); National Association of City Transportation Officials (NACTO). Guia Global de Desenho de Ruas. $1^{\text {a }}$ ed. São Paulo: SENAC, 2018, $398 \mathrm{p}$.

GOMES, Julia D.; GOMES, Leticia D.; MELLO, Márcia M. C. Urbanismo tático e o direito à cidade. Revista Políticas Públicas e Cidades. Belo Horizonte, v.8, n.4, p. 40-51, jul./set.,2019.

GUIMARÃES, P. P. Configuração urbana: evolução, avaliação, planejamento e urbanização. São Paulo: ProLivros, 2004.

JACOBS, Jane. Morte e a vida das grandes cidades. $3^{\text {a }}$ ed. São Paulo: Martins Fontes, 2011.

KELLEY, T.; KELLEY, D. Creative Confidence: Unleashing the Creative Potential Within Us All. [s.I]: William Collins, 2013, 306 p.

LESTINGE, Sandra Regina. Olhares de educadores ambientais para estudo do meio e pertencimento. 2004. $247 \mathrm{f}$. Tese (Doutorado em Recursos Florestais). Escola Superior de Agricultura "Luiz de Queiroz", Universidade de São Paulo, Piracicaba, 2004.

LYDON, Mike; GARCIA, Anthony. Tactical Urbanism: Short-term action for Longterm change. [s.]: Island Press, 2015, $256 \mathrm{p}$.

MACÊDO, Amanda Florêncio; ALMEIDA, André Moraes. O espaço público frente ao urbanismo tático: o caso das Praias do Capibaribe. In: Congresso Internacional Espaços Públicos, 1. 2018. Anais [...]. Recife, 2018, p. 1 - 10.

MONTANER, Josep.; MUXÍ, Zaida. Arquitetura e política: ensaios para mundos alternativos. São Paulo: Gustavo Gili, 2014.

MORAES, F. A.; GOUDARD, B. e OLIVEIRA, R. Reflexões sobre a cidade, seus equipamentos urbanos e a influência destes na qualidade de vida da população. Revista Internacional Interdisciplinar INTERthesis. Florianópolis, SC, v. 5, n. 2, p. 93-103, 2008.
ORNSTEIN, Sheila; RÓMERO, Marcelo. Avaliação pós-ocupação do ambiente construído. São Paulo: Studio Nobel, 1992.

PORTELA, R. de S. Planejamento, participação popular e gestão de políticas urbanas: a experiência do projeto macrodrenagem da Bacia do Una (BELÉM-PA). Dissertação (Mestrado). Mestrado Internacional em Planejamento do Desenvolvimento. Universidade Federal do Pará, 2005.

RIBEIRO, Ana Clara Torres. Por uma sociologia do presente: ação, técnica e espaço. Rio de Janeiro: Letra Capital, 2013, 5 v.

ROMANINI, Anicoli. Planejamento urbano \& equipamentos urbanos: o caso de Passo Fundo/RS. Revista de Arquitetura IMED. Passo Fundo, RS. v. 1, n. 1, p. 58-70, jan./jul. 2012.

SANTOS, Carlos Nelson F. dos. A cidade como um jogo de cartas. São Paulo: Projeto, 1988.

SANTOS, Fabiana Pimentel; DAVEL, Eduardo. Pesquisa-ação em prol da cooperação interorganizacional: debates, repercussões e práticas. Revista de estudos organizacionais e sociedade, Belo Horizonte, MG, v. 5, n. 13, p. 723-791, 2018.

VARGAS, Heliana C. \& CASTILHO, Ana Luis H. Intervenções em Centros Urbanos: objetivos Estratégias e Resultados. São Paulo: Manole. 2006.

VARGAS, Heliana C. Comércio: Localização estratégica ou estratégia na Localização. 1992. Tese (Doutorado em Estruturas Ambientais Urbanas). Universidade de São Paulo, Faculdade de Arquitetura e Urbanismo (FAUUSP). São Paulo, 1992. 